\title{
UMJETNA INTELIGENCIJA U RADIOLOGIJIF ETIČKI PROBLEMI
}

\author{
Darjan Franjić' ${ }^{1,2}$, Miro Miljko ${ }^{2,3}$ \\ ${ }^{1}$ Klinika za onkologiju, Sveučilišna klinička bolnica Mostar \\ ${ }^{2}$ Fakultet zdravstvenih studija Sveučilišta u Mostaru \\ ${ }^{3}$ Odjel za radiologiju, Sveučilišna klinička bolnica Mostar \\ 88000 Mostar Bosna i Hercegovina
}

Rad je primljen 09.09.2020. Rad je recenziran 14.09.2020. Rad je prihvaćen 19.09.2020.

\section{SAŽETAK}

Umjetna inteligencija je dio računalne znanosti koji se bavi razvojem sposobnosti računala da obavljaju zadaće za koje je potreban neki oblik inteligencije. Kao znanstvena disciplina uključuje nekoliko pristupa i tehnika, kao što su strojno učenje, strojno zaključivanje i robotika. Posljednjih godina zabilježen je strelovit razvoj umjetne inteligencije u medicini, naročito u radiologiji. Stručnjaci koji se bave umjetnom inteligencijom u medicini smatraju da bi radiologija sljedećih godina mogla postati okosnica umjetne inteligencije u zdravstvu. Unatoč mnogim prednostima koje umjetna inteligencija u radiologiji nudi, postoje mnoge moralne nedoumice vezane za zaštitu podataka, dobrovoljni informirani pristanak, neplaniranu pristranost i snošenje odgovornosti. Etički problemi umjetne inteligencije u radiologiji nisu još u potpunosti definirani te su mnoga pitanja i dalje otvorena. Pojam etična umjetna inteligencija se upotrebljava za označivanje razvoja, uvođenja i upotrebe umjetne inteligencije koja osigurava usklađenost s etičkim normama, uključujući moralna prava, etička načela i povezane temeljne vrijednosti. Umjetna inteligencija se treba razvijati, uvoditi i upotrebljavati na način kojim se poštuju etička načela kao što su poštovanje ljudske autonomije, sprječavanje nastanka štete, pravednost i objašnjivost. Činjenica je da pretjerane regulative mogu usporiti razvoj umjetne inteligencije i time utjecati na tehnološki razvoj i napredak medicine i radiologije. Primjena umjetne inteligencije u radiologiji se ipak mora temeljiti na pomno pripremljenim zakonima koji će omogućiti da umjetna inteligencija bude sigurna, jasna i objašnjiva. Cilj ovog rada je na temelju dosadašnjih spoznaja pobliže objasniti pojam umjetne inteligencije i analizirati etičke probleme vezane za primjenu umjetne inteligencije u radiologiji.

Ključne riječi: umjetna inteligencija, radiologija, etički problemi

Autor za korespondenciju:

Darjan Franjić, mag. rad. techn., doktorand

E-mail: darjan.franjic@fzs3.sum.ba 


\section{UVOD}

Na temelju zamisli da se čovjeku olakša posao pomoću strojeva, sredinom prošlog stoljeća nastala je umjetna inteligencija (1). Umjetna inteligencija je dio računalne znanosti koji se bavi razvojem sposobnosti računala da obavljaju zadaće za koje je potreban neki oblik inteligencije, tj. da se mogu snalaziti u novim prilikama, učiti nove koncepte, donositi zaključke, razumjeti prirodni jezik, raspoznavati prizore i dr. (2). Otkako je prvi put upotrijebljen u medicinske svrhe, koncept umjetne inteligencije pokazao se vrlo privlačnim za zdravstvenu skrb, posebno radiologiju. S razvojem tehnologije, različiti oblici umjetne inteligencije pronašli su put ka primjeni u raznim medicinskim specijalnostima (3). Stručnjaci koji se bave umjetnom inteligencijom smatraju da radiologija predstavlja granu medicine u kojoj će se značajna primjena umjetna inteligencije najprije dogoditi, ponajprije zbog njene ovisnosti o tehnološkom napretku (4). Pohranjivanje velikog skupa podataka, jača i brža računala, brže uspostavljanje dijagnoze i algoritmi dubokog učenja su mogućnosti koje tehnologija umjetne inteligencije nudi (5).

Prilikom primjene umjetne inteligencije u radiologiji ne smiju se zanemariti etička načela pacijenata (6). Izgradnja etičke umjetne inteligencije zahtijeva i etički pristup u izgradnji samog sustava i plan za etički razvoj sustava umjetne inteligencije $(5,6)$. Dosadašnja istraživanja pokazuju da je vrednovanje različitih postupaka s obzirom na to koliko dobro ostvaruju različite potrebe za različite ljude izuzetno složen proces, ali se može provesti pomoću algoritama koji uravnotežuju mnoštvo ograničenja na kojima se temelje djelovanja koja zadovoljavaju potrebe većine ljudi. Takvi algoritmi mogu se učinkovito obraditi neuronskim mrežama i drugim metodama umjetne inteligencije (7). Cilj ovog preglednog rada je na temelju dosadašnjih spoznaja pobliže objasniti pojam umjetne inteligencije i analizirati etičke probleme vezane za primjenu umjetne inteligencije $\mathrm{u}$ radiologiji.

\section{SUSTAVI UMJETNE INTELIGENCIJE}

Sustavi umjetne inteligencije jesu softver, ponekad i hardver, koji su dizajnirali ljudi. Djeluju u fizičkoj ili digitalnoj dimenziji putem zapažanja okruženja kroz stjecanje podataka, tumačenja prikupljenih strukturiranih ili nestrukturiranih podataka, zaključivanja o znanju ili obrade informacija izvedenih iz tih podataka i odlučivanja o najboljoj radnji (ili radnjama) koju treba poduzeti kako bi se ostvario određeni cilj. Mogu se koristiti simboličkim pravilima ili naučiti numerički model te mogu i prilagoditi svoje ponašanje analiziranjem načina na koji su svojim prethodnim radnjama utjecali na okruženje. Uključuje nekoliko pristupa i tehnika, kao što su strojno učenje (duboko učenje i pojačano učenje), strojno zaključivanje i robotika (8).

Metode dubokog učenja svoju primjenu pronalaze u važnim područjima umjetne inteligencije poput računalnog vida, obrade prirodnog jezika, razumijevanja govora i zvučnih signala. Algoritmi dubokih neuronskih mreža mogu čak nadmašiti ljudsku točnost u područjima poput računalnog vida. Pojava metode dubokog učenja je olakšavanjem obrade podataka povećala dostupnost velikog skupa podataka. Sustav velikih podataka (engl. Big Data) odnosi se na zbirku podataka koje konvencionalnim softverskim alatima nije moguće zabilježiti i obraditi $\mathrm{u}$ određenom vremenskom razdoblju $(9,10)$. Pod učenjem podrazumijeva se iterativni postupak podešavanja vrijednosti težinskih faktora na osnovu pogreške između proračunate vrijednosti modelom i stvarne vrijednosti mjerene veličine. Učenje, odnosno podešavanje težinskih faktora odvija se prema jednom od pravila učenja kao što je tzv. pravilo širenja unatrag ili algoritam unatražne propagacije izlazne pogreške (engl. back propagation) (11). Važne značajke dubokih neuronskih mreža su aktivacijske funkcije, kao što je ispravljena linearna jedinica (ReLU, engl. rectified linear unit). Opća struktura konvolucijske neuronske mreže se sastoji od ulaza (radiološka slika), konvolucijskih slojeva, slojeva sažimanja, jednodimenzionalnih potpuno povezanih slojeva i izlaza (klasifikacija radiološke slike) (Slika 1) (12). 


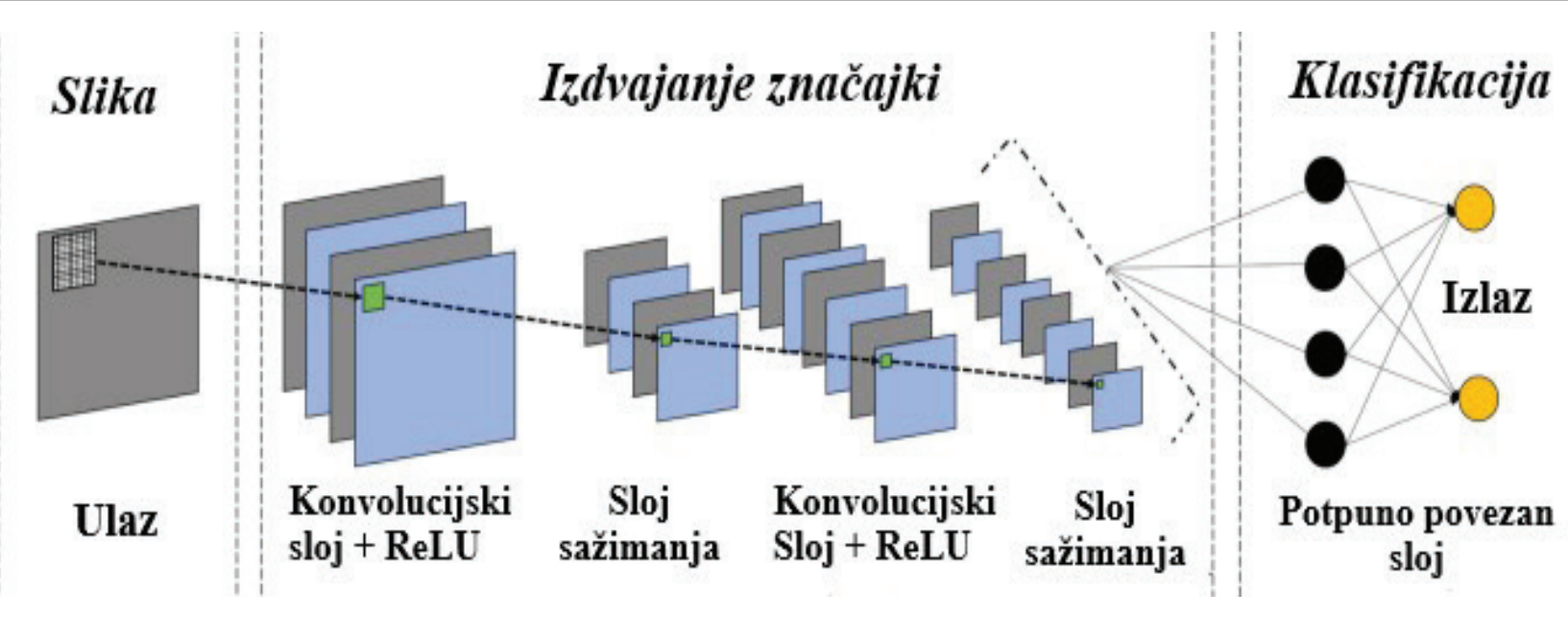

Slika 1. Proces klasifikacije radiološke slike tehnikom dubokih neuronskih mreža (12)

Danas, zahvaljujući intenzivnom razvoju teorije i praktične primjene neuronskih mreža, na raspolaganju nam stoje brojne strukture i algoritmi učenja. Prilikom jednog prolaza informacije kroz neuronsku mrežu generira se vrijednost koja se potom uspoređuje sa stvarnom vrijednošću. Na temelju razlike stvarne i izračunate vrijednosti, korigiraju se težinski faktori. Korekcijom težinskih faktora neuronska mreža uči predviđati stvarne vrijednosti te se smanjuje razlika stvarnih i predviđenih vrijednosti izlaznih veličina. Kriterij pogreške govori o kvaliteti i robusnosti (generalizaciji) mreže. Provjerom mreže na novom skupu podataka - skupu za provjeru, sprječava se "pretreniranje" (engl. overfitting) mreže prilikom učenja. Pretreniranje se javlja kad mreža s visokom točnošću opisuje vladanje podataka na skupu podataka na kojem je razvijana, dok izvan tog skupa pokazuje lošije rezultate. Kako bi se to spriječilo, učenje neuronskih mreža treba se zaustaviti u trenutku kada pogreška provjere (engl. testing error) počne rasti (11).

\section{ETIKA UMJETNE INTELIGENCIJE}

Etika umjetne inteligencije usmjerena je na normativna pitanja koja se javljaju u vezi s dizajnom, razvojem, uvođenjem i upotrebom umjetne inteligencije. Pojam etična umjetna inteligencija se upotrebljava za označivanje razvoja, uvođenja i upotrebe umjetne inteligencije koja osigurava usklađenost s etičkim normama, uključujući temeljna prava kao što su moralna prava, etička načela i povezane temeljne vrijednosti. Neovisna stručna skupina na visokoj razini o umjetnoj inteligenciji izradila je dokument objavljen 2018. godine koji se odnosi na etičke smjernice za pouzdanu umjetnu inteligenciju. Prema ovom dokumentu pouzdana umjetna inteligencija ima tri sastavnice koje trebaju biti ispunjene tijekom cijelog životnog ciklusa sustava. Umjetna inteligencija bi trebala biti:

zakonita i poštovati sve primjenjive zakone i propise;

etična i osigurati poštovanje etičkih načela i vrijednosti;

otporna i iz tehničke i iz socijalne perspektive jer sustavi umjetne inteligencije, čak is dobrim namjerama, mogu uzrokovati nenamjernu štetu.

U idealnom su slučaju sve tri sastavnice usklađene i preklapaju se u svojem djelovanju. Ako se u praksi među njima pojave napetosti, društvo bi ih trebalo nastojati uskladiti. Najnovije europske smjernice nalažu da sustave umjetne inteligencije treba razvijati, uvoditi i upotrebljavati na način kojim se poštuju etička načela kao što su: poštovanje ljudske autonomije, sprječavanje nastanka štete, pravednost i objašnjivost (8). Termin „pouzdana umjetna inteligencija" ne odnosi se samo na pouzdanost samog sustava umjetne inteligencije, već obuhvaća i pouzdanost svih procesa i sudionika koji su dio životnog ciklusa sustava (13). 


\section{UMJETNA INTELIGENCIJA U RADIOLOGIJI}

Napredak u razvoju algoritama i aplikacija umjetne inteligencije u kombinaciji s lakim pristupom računalnim podatcima omogućava primjenu umjetne inteligencije $\mathrm{u}$ medicini, i to u zadatcima koji se odnose na donošenje medicinskih odluka, uz obećavajuće rezultate (14). Algoritmi umjetne inteligencije se koriste $\mathrm{u}$ kompjutoriziranoj tomografiji u detekciji karcinoma debelog crijeva (15) kao i u magnetnoj rezonanci pri segmentaciji tumora mozga (16). Najnovija istraživanja pokazuju da algoritmi umjetne inteligencije identificiraju rak dojke s približno $90 \%$ točnosti u kombinaciji s analizom radiologa. Zabilježeni su i primjeri u kojima je rak dojke otkriven pomoću sustava umjetne inteligencije, dok $u$ istog pacijenta sedam prethodnih radiologa samostalno (bez korištenja tehnike umjetne inteligencije) nije dijagnosticiralo karcinom (17). Hinton i sur. su proveli istraživanje $u$ kojem su usporedili točnost standardnog sustava za radiološku klasifikaciju promjena u dojci BI-RADS (engl. Breast Imaging-Reporting and Data System) i algoritama dubokog učenja u dijagnosticiranju karcinoma dojke. Rezultati njihovog istraživanja pokazuju da je BIRADS sustavom izražena točna dijagnoza u $63 \%$ slučajeva, dok je algoritmima dubokog učenja u 75 \% slučajeva izražena točna dijagnoza (Slika 2) (18).

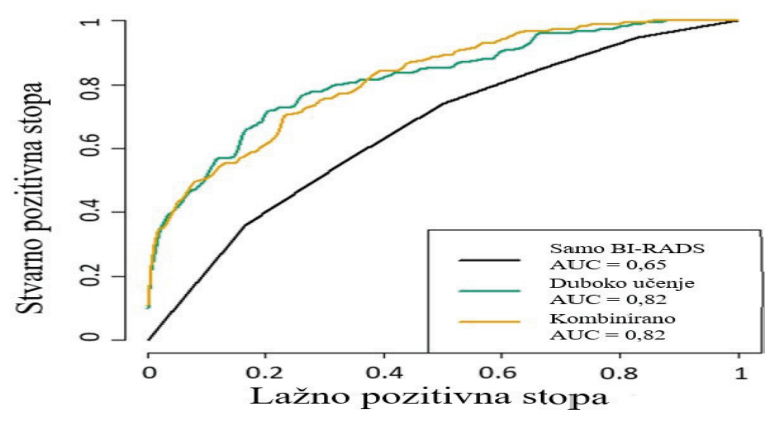

Slika 2. Ocjena točnosti klasifikacije sustava za kategoriziranje mamografskih nalaza BI-RADS (engl. Breast Imaging-Reporting and Data System) i algoritama dubokog učenja (18)

Najnovija istraživanja pokazuju da algoritmi umjetne inteligencije pomažu i u dijagnostici upa- le pluća uzrokovane teškim akutnim respiratornim sindromom koronavirus 2. Algoritam umjetne inteligencije je funkcionalan i kada pacijent ima osnovne zdravstvene probleme, kao što je ugrađeni pacemaker ili uvećano srce (19). Ometajući čimbenici za implementaciju umjetne inteligencije su nekonzistentna tehnološka izvedba, nestrukturirani implementacijski procesi, nesigurna i nedovoljno dokazana dodatna vrijednost za kliničku praksu te velika varijanca u odnosu na prihvaćanje i vjerovanje $u$ nalaze dobivene umjetnom inteligencijom (20).

Umjetna inteligencija podrazumijeva razvoj uobičajene nomenklature te učinkovitiji i kvalitetniji način prijenosa radioloških slika. Programi nadzora umjetne inteligencije mogu pomoći radiolozima $u$ određivanju prioritetnih nalaza za očitavanje tako što će metodama dubokog učenja otkriti sumnjive ili pozitivne slučajeve. Algoritmi umjetne inteligencije mogu koristiti za ekstrakciju prognostičkih informacija iz slika koje nisu vidljive "golim“ okom, što potencijalno povećava dijagnostičku i prognostičku vrijednost (21). Jedan od primjera primjene umjetne inteligencije $\mathrm{u}$ radiologiji je Modernizing Medicine sustav. To je baza podataka koja bilježi 14 milijuna zapisa bolesnika iz 3700 raznih izvora i moguće se od bilo kuda povezati na nju i pretraživati je, te postoji on line baza elektroničkih medicinskih kartona razvrstanih po specijalnosti s podrškom za sve tipove i načine pristupa i pretraživanja. Razvijen je njihov tzv. elektronički medicinski asistent koji pomaže liječnicima u dijagnostici. Ako se pojavi bolesnik s nekim do tada neobičnim simptomima, pretragom i analizom lakše će se odabrati optimalno liječenje ukoliko je bilo kada i bilo gdje zabilježen takav slučaj (22). Dodatni primjer umjetne inteligencije u radiologiji je računalom (potpomognuta) detekcija (CAD, engl. computer-aided detection) karcinoma te automatska segmentacija organa prilikom 3D postprocesuiranja (23). Tehnologija CAD se često koristi i u 3D digitalnoj subtrakcijskoj angiografiji pri detekciji intrakranijalnih aneurizmi, što je dovelo do bolje vizualizacije vaskularnog stabla čime je napravljen napredak u smanjenju slikovnih artefakata i postavljanju dijagnoze (24). Tehnika strojnog učenja u kombinaciji s magnetno-rezonan- 
tnom perfuzijom mozga se pokazala učinkovitom u dijagnostici neuroloških poremećaja, kao što je Alzheimerova bolest (25).

Stručnjaci smatraju da će se uspješnost implementacije umjetne inteligencije $\mathrm{u}$ radiologiji očitovati u uspostavljanju pouzdanije dijagnoze, bržem protokolu rada, boljem ishodu za pacijente i boljoj kvaliteti radnog života za radiologe. Nadalje, smatra se da će primjena umjetne inteligencije doprinijeti porastu potražnje za radiološkim uslugama (26). Pojedini radiolozi smatraju da će tehnologija umjetne inteligencije doprinijeti poboljšanju usluge, ali i nejasnoćama u odnosu na daljnju specifikaciju poslova (27). U odnosu na izjave i mišljenja da se radiolozi prekomjerno oslanjaju na pomoć tehnologije u svom radu i da će tehnologija zamijeniti radiologe, stručnjaci navode da oni koji tako misle u potpunosti ne prepoznaju vrijednost umjetne inteligencije, ponajviše u smislu pomoći radiolozima u koordinaciji i integraciji informacija, identifikaciji pacijenata za skrining preglede, odabiru prioritetnih pacijenata za hitnu interpretaciju, standardizaciji nalaza i karakterizaciji bolesti (23).

\section{ETIČKI PROBLEMI UMJETNE INTELIGENCIJE U RADIOLOGIJI}

Medicina je područje u kojem nove tehnologije oduvijek izazivaju i podrazumijevaju mnoge moralne nedoumice, a koje su osobito uočljive u kontekstu zaštite i privatnosti podataka (28). Osim što bi se podatci prilikom primjene umjetne inteligencije mogli početi koristiti za komercijalnu svrhu, mogu doći u posjed osjetljivih dijagnoza koje pacijenti nisu spremni dijeliti s javnošću. Veliki etički problem umjetne inteligencije $u$ radiologiji jest snošenje odgovornosti prilikom potencijalnih grešaka u dijagnostici. S ovim problemom se susreću i druge ekspertne grane medicine (29). Lu i sur. navode da postoji zabrinutost od pretjeranog oslanjanja liječnika na tehnologiju umjetne inteligencije, narušavanja njihove spremnosti da pamte stara i stječu nova medicinska znanja te gubitka vještine fizičkog pregleda i suosjećajne komunikacije s pacijentima (30). Dodatne komplikacije predstavlja praksa u svezi informiranog pristanka pacijenta. Problem pred- stavlja objašnjenje pacijentu načina uspostavljanja dijagnoze pomoću algoritama umjetne inteligencije. Zbog toga će uvođenje novih medicinskih tehnologija utemeljenih na umjetnoj inteligenciji dovesti do moralnih dilema koje će zahtijevati određene izmjene ili prilagodbe postojećih kodeksa medicinske etike. Suradnjom stručnjaka iz Europskog radiološkog društva (engl. European Society of Radiology) i Kanadskog udruženja radiologa (engl. Canadian Association of Radiologists) te Američkog udruženja fizičara u medicini (engl. American Association of Physicists in Medicine) 2019. godine objavljena su etička načela u kojima je posebna pažnja obraćena na zaštitu podataka, algoritme i „naučene“ modele umjetne inteligencije kao i na poštivanje etičkih načela u praksi radiološke umjetne inteligencije (31). Etika korištenja podataka se odnosi na poštivanje povjerenja pacijenata prilikom prikupljanja, upravljanja i procjenjivanja prikupljenih podataka (32).

Radiološke slike predstavljaju medicinske dijagnostičke podatke koji su posebno osjetljivi na narušavanje privatnosti pacijenta. Stoga treba voditi računa o etičkoj zaštiti prilikom korištenja takvih podataka u svrhe dubokog učenja. Radiološki snimci mogu otkriti suštinu informacije više od same riječi, poput podataka sadržanih u vlastitom genomu pojedinca (33). Učinjena šteta zbog kršenja privatnosti može biti posljedična, tijekom koje pacijent doživljava diskriminaciju, poniženje ili povećanje troškova osiguranja. Šteta može biti i deontološka, prilikom koje pacijent kao pojedinac ne mora osjetiti izravno negativne posljedice kršenja privatnosti podataka, ali se može dogoditi povreda etičke dužnosti koju su zdravstveni djelatnici prema pacijentu dužni poštovati (34). Postoji briga i zabrinutost u odnosu na sposobnost algoritama inteligencije da odražavaju ljudsku nenamjernu pristranost od samog početka u odlučivanju i donošenju dijagnoze i ostalih medicinskih odluka. Prvenstveno zato što čovjek mora kodirati bilo koji program ili sustav umjetne inteligencije (35). Postoje etički problemi koji se odnose na sukob interesa u svezi radiologa i razvoja umjetne inteligencije u radiologiji. $U$ radu iz 2016. godine postavlja se pitanje o potrebi za radiolozima nakon što IBM (engl. International Business Machine), 
američka tvrtka koja se bavi razvojem računarstva i informacijskih tehnologija, razvije aplikacije umjetne inteligencije na osnovi analize kupljenih baza radioloških slika. Pojedini autori predviđaju nestanak pojedinih medicinskih djelatnosti pojavom umjetne inteligencije te da će određeni liječnici možda biti potrebni za učenje robota, dok će ostali evolucijski „izumrijeti“, baš kao i neke druge djelatnosti tijekom povijesti (36). Geofrey Hinton, kanadski kognitivni psiholog i računalni znanstvenik, šokirao je svjetsku medicinsku javnost izjavivši da će umjetna inteligencija u potpunosti preuzeti radiologiju (37).

Realnost je ipak drugačija. Većina znanstvenika i stručnjaka navodi da se liječnička prosudba, kreativnost ili empatija nikada ne mogu zamijeniti. Smatra se da će algoritmi umjetne inteligencije moći predložiti određenu dijagnozu ili terapiju, ali je radiolog taj koji će i dalje donositi konačne odluke (38). Carl Lunglotz, profesor radiologije i direktor centra za umjetnu inteligenciju u medicini i radiološkoj dijagnostici, navodi da je razmišljanje da će sustavi umjetne inteligencije zamijeniti radiologe potpuno pogrešno. Prema njemu, radiolozi koji koriste sustave umjetne inteligencije će zamijeniti radiologe koji ih ne koriste (39). Nedvojbena korist umjetne inteligencije moći se postići kada se pouzdano procijene potencijalne negativne posljedice njene upotrebe $\mathrm{i}$ kada se odrede načini na koji će se od njih zaštititi ljudi i njihova etička načela (32).

\section{ZAKLJUČAK}

Implementacija umjetne inteligencije može donijeti veliku korist u radiologiji, naročito u otkrivanju i liječenju karcinoma, unaprjeđenju kvalitete radiološke usluge i ubrzavanju protokola rada. Činjenica je da široka primjena umjetne inteligencije u radiologiji može donijeti i niz negativnih posljedica i stvoriti niz problema, naročito etičkih. Iz dosadašnjih istraživanja vidljivo je da etički problemi umjetne inteligencije u radiologiji nisu riješeni i da su mnoga pitanja i dalje otvorena, kao što je zaštita privatnosti podataka, informirani pristanak pacijenta, sukob interesa i snošenje odgovornosti. Svijest o etičkim problemima umjetne inteligencije kod znanstvenika i stručnjaka postoji, što pokazuje porast objavljenih publikacija na ovu temu u posljednjih deset godina. Udruženja radiologa i istraživački timovi zaduženi za razvoj umjetne inteligencije u najrazvijenijim državama svijeta rade na pripremi novih zakona koji su prilagođeni modernim vremenima i digitalnim tehnologijama. Činjenica je da pretjerane regulative mogu usporiti razvoj umjetne inteligencije i time utjecati na tehnološki razvoj i napredak medicine i radiologije. Primjena umjetne inteligencije u radiologiji se ipak mora temeljiti na pomno pripremljenim zakonima koji će omogućiti da umjetna inteligencija bude sigurna, jasna i objašnjiva.

\section{LITERATURA}

1. Putica M. Umjetna inteligencija: dvojbe suvremenog razvoja. Hum [Internet]. 2018 [pristupljeno 1.06.2020.];13(20):198-213.

Dostupno na: https://hrcak.srce.hr/219733

2. Prister V. Umjetna inteligencija. Media, Culture and Public relations [Internet]. 2019 [pristupljeno 01.08.2020.];10(1):67-72. Dostupno na: file:///C:/Users/Korisnik/Downloads/ Prister\%20(1).pdf

3. Grčić-Filipović L, Đerke F. Umjetna inteligencija u radiologiji. Rad Hrvatske akademije znanosti i umjetnosti. Medicinske znanosti. 2019;537:46-47.

4. Kohli M, Geis R. Ethics, artificial intelligence, and radiology. J Am Coll Radiol. 2018;15(9):1317-1319.

5. Thagard P. Ethical coherence. Philosophical Psychology. 2008;11(4):405-422.

6. Finlay K. Robot radiologists will soon analyse your x-rays. Wired.com. [Internet]. 2015 Lis 27 [pristupljeno 30.07.2020.]. Dostupno na: https://www.wired.com/2015/10/robot-radiologists-are-going-to-start-anlyzing-x-rays/

7. Hosny A, Parmar C, Quackenbush J, Schwartz LH \& Aerts HJWL. Artificial intelligence in radiology. Nat Rev Cancer. 2018;18(8):500-510.

8. Stručna skupina na visokoj razini o umjetnoj inteligenciji. Bruxelles: Etičke smjernice za pouzdanu umjetnu inteligenciju [Internet]; 2018 [pristupljeno 15.07.2020.]. Dostupno na: https:// www.europarl.europa.eu/meetdocs/2014_2019/ 
plmrep/COMMITTEES/JURI/DV/2019/11-06/

Ethics-guidelines-AI HR.pdf

9. Teigens V. Umjetna opća inteligencija. Prvo izdanje [Internet]. Cambridge Stanford Books. 2008 [pristupljeno 02.07.2020.]. Dostupno na: https://books.google.ba/books/about/Umjetna_op\%C4\%87a_inteligencija.html?id=zR3NDwAAQBAJ\&redir_esc $=y$

10. Deo RC. Machine learning in medicine. Circulation. 2015;132(20):1920-1930.

11. Ujević Andrijić Ž. Umjetne neuronske mreže. Osvježimo znanje, Kem Ind [Internet]. 2019 [pristupljeno 13.08.2020.];68(5-6):219-220. Dostupno na: https://hrcak.srce.hr/220716

12. Koçak B, Durmaz EŞ, Ateş E, Kılıçkesmez Ö. Radiomics with artificial intelligence: a practical guide for beginners. Diagn Interv Radiol [Internet]. 2019 [pristupljeno 13.08.2020.];25(6):485495. Slika 10, Over-simplified illustration of artificial neural network, particularly deep learning; p. 9. Dostupno na: https://www.ncbi.nlm. nih.gov/pmc/articles/PMC6837295/pdf/dir-256-485.pdf

13. Siau K, Wang W. Building trust in artificial intelligence, machine learning, and robotics. Cutter Business Technology Journal. 2018;(31):47-53.

14. King BF. Guest editorial: discovery and artificial intelligence. AJR Am J Roentgenol. 2017;209:1189-1190.

15. Pesapane F, Codari M, Sardanelli F. Artificial intelligence in medical imaging: threat or opportunity? Radiologists again on the wavefront of innovation in medicine. Eur Radiol Exp. 2018;2:35.

16. Summers RM, Beaulieu CF, Pusanik LM, Malley JD, Jeffrey RB, Glazer DI, et al. Automated polyp detector for CT colonography: feasibility study. Radiology. 2000;216:284-290.

17. Geras KJ, Mann RM, Moy L. Artificial intelligence for mammography and digital breast tomosynthesis: current concepts and future perspectives. Radiology. 2019 Nov;293(2):246-259.

18. Hinton B, Ma L, Mahmoudzadeh PA, Malkov S, Fan B, Greenwood H, et al. Deep learning networks find unique mammographic differen- ces in previous negative mammograms between interval and screen-detected cancers: a case-case study. Cancer Imaging [Internet]. 2019 [pristupljeno 13.08.2020.];19(1):41. Slika 3, ROC Curves interval vs screen-detected cancer classification using BI-RADS density alone (Only BI-RADS) vs using the deep learning predictions (Deep Learning) vs using both as predictors (Combined); p. 6. Dostupno na: https://www. ncbi.nlm.nih.gov/pmc/articles/PMC6589178/

19. Neri E, Miele V, Coppola F, Grassi R. Use of CT and artificial intelligence in suspected or $\mathrm{CO}$ VID-19 positive patients: statement of the Italian Society of Medical and Interventional Radiology. Radiol Med. 2020;125(5):505-508.

20. Strohm L, Hehakaya C, Ranschaert ER, Boon WPC, Moors EHM. Implementation of artificial intelligence (AI) applications in radiology: hindering and facilitating factors. Eur Radiol. 2020;10.

21. Thrall JH, Li X, Li Q, Cruz C, Do S, Dreyer K, et al. Artificial intelligence and machine learning in radiology: opportunities, challenges, pitfalls, and criteria for success. Am Coll Radiol. 2018;15(3):504-508.

22. White T. The doctor's handbook, Pt. 1. Četvrto izdanje [Internet]. Radcliffe Publishing, Oxford, New York [pristupljeno 16.06.2020.]. Dostupno na: https://www.amazon.co.uk/Doctors-Handbook-Pt-1/dp/184619458X

23. Loria K. Putting the AI in radiology. Radiology Today. 2020;19(1):10.

24. Franjić D, Mašković J. Usporedba 3D tehnike i digitalne subtrakcijske angiografije $\mathrm{u}$ detekciji intrakranijalnih aneurizmi i njihove lokalizacije. Zdravstveni glasnik [Internet]. 2018 [pristupljeno 04.08.2020.];1:23-32. Dostupno na: https:// fzs.sum.ba/sites/default/files/Glasnik\%207.pdf

25. Perez-Ramirez U, Arana E, Moratal D. Computer-aided detection of brain metastases using a three-dimensional template-based matching algorithm. Conf Proc IEEE Eng Med Biol Soc. 2014;2384-2387.

26. Liew $\mathrm{C}$. The future of radiology augmented with artificial intelligence: a strategy for success. European Journal of Radiology. 2018;102:152-6. 
27. Syed AB, Zoga AC. Artificial intelligence in radiology: current technology and future directions. Semin Musculoskelet Radiol. 2018;22(5):540545.

28. Bračanović T. Etički izazovi umjetne inteligencije i robotike. Povijest i filozofija tehnike [Internet]. 2019 [pristupljeno 17.07.2020.]. Dostupno na: https://tomislav.bracanovic.ifzg.hr/wpcontent/ uploads/2020/03/Bracanovic_Eticki_izazovi_ UI_robotika.pdf

29. Pesapane F, Volonte C, Codari M, Sardanelli F. Artificial intelligence as a medical device in radiology: ethical and regulatory issues in Europe and the United States. Insights into imaging. 2018;9:745-753.

30. Lu J. Will medical technology deskills doctors? International Education Studies. 2016;9:7.

31. Geis JR, Brady AP, Wu CC, Spencer J, Ranschaert E, Jaremko JL, et al. Ethics of artificial intelligence in radiology: summary of the joint European and North American multisociety statement. Can Assoc Radiol J. 2019;70(4):329334.

32. Mittelstadt BD, Floridi L. The ethics of Big Data: current and foreseeable issues in biomedical contexts. Sci Eng Ethics. 2016;22(2):303-341.

33. Brothers KB, Rothstein MA. Ethical, legal and social implications of incorporating personalized medicine into healthcare Per Med. 2015;12:43-51.
34. Price WN, Cohen IG. Privacy in the age of medical big data. Nat Med. 2019;25:37-43.

35. Char DS, Shah NH, Magnus D. Implementing machine learning in health care-addressing ethical challenges. N Engl J Med. 2018;378:981983.

36. Mohan CSM. Artificial intelligence in radiology - are we treating the image or the patient? Indian J Radiol Imaging. 2018 [pristuljeno 15.06.2020.]. Dostupno na: https://www.ncbi. nlm.nih.gov/pmc/articles/PMC6038229/

37. Slade-Šilović I. Medicinska informatika: Razvoj umjetne inteligencije u zdravstvu i zdravstvo sutrašnjice. Medix. 2016 [pristupljeno 07.06.2020.];121-122. Dostupno na: https://bib. irb.hr/datoteka/914096.Medix_Slade-Silovic. pdf

38. Mora L, Delsanto S, Loredana C. Artificial intelligence in medical imaging: from theory to clinical practice. Prvo izdanje [Internet]. CRC Press Taylor \& Francis Group. 2019 [pristupljeno 06.06.2020.]. Dostupno na: https://www.researchgate.net/publication/337559458_Artificial_Intelligence_in_Medical_Imaging_From_Theory_to_Clinical_Practice/citation/download

39. Langlotz CP. Will artificial intelligence replace radiologists? Radiol Artif Intell. 2019;1:e190058. 